\title{
Anemia and red blood cell transfusion practice in prolonged mechanically ventilated patients admitted to a specialized weaning center: an observational study
}

\author{
Alessandro Ghiani ${ }^{1 *}$ (D), Alexandros Sainis ${ }^{1,2}$, Georgios Sainis ${ }^{3}$ and Claus Neurohr ${ }^{1,4}$
}

\begin{abstract}
Background: The impact of anemia and red blood cell (RBC) transfusion on weaning from mechanical ventilation is not known. In theory, transfusions could facilitate liberation from the ventilator by improving oxygen transport capacity. In contrast, retrospective studies of critically ill patients showed a positive correlation of transfusions with prolonged mechanical ventilation, increased mortality rates, and increased risk of nosocomial infections, which in turn could adversely affect weaning outcome.
\end{abstract}

Methods: Retrospective, observational study on prolonged mechanically ventilated, tracheotomized patients $(n=378)$, admitted to a national weaning center over a 5 year period. Medical records were reviewed to obtain data on patients' demographics, comorbidities, blood counts, transfusions, weaning outcome, and nosocomial infections, defined according to the criteria of the U.S. Centers for Disease Control and Prevention. The impact of RBC transfusion on outcome measures was assessed using regression models.

Results: Ninety-eight percent of all patients showed anemia on admission to the weaning center. Transfused and non-transfused patients differed significantly regarding disease severity and comorbidities. In multivariate analyses, RBC transfusion, but not mean hemoglobin concentration in the course of weaning, was independently correlated with weaning duration (adjusted $\beta$ 12.386, 95\% Cl 9.335-15.436; $p<0.001$ ) and hospital length of stay (adjusted $\beta$ $16.116,95 \% \mathrm{Cl} 8.925-23.306 ; p<0.001$ ); there was also a trend toward increased hospital mortality (adjusted odds ratio [OR] 2.050, 95\% Cl 0.995-4.224; $p=0.052)$, but there was no independent correlation with weaning outcome or nosocomial infections. In contrast, hemoglobin level on the day of admission to the weaning center was independently associated with hospital mortality (adjusted OR 0.956, 95\% Cl 0.924-0.989; $p=0.010$ ), appearing significantly elevated at values below $8.5 \mathrm{~g} / \mathrm{dl}$ (AUC 0.670, 95\% Cl 0.593-0.747; $p<0.001$ ).

Conclusions: A high percentage of prolonged mechanically ventilated patients showed anemia on admission to the weaning center. RBC transfusion was independently correlated with worse outcomes. Since transfused patients differed significantly regarding their clinical characteristics and comorbidities, RBC transfusion might be an indicator of disease severity rather than directly impacting patient prognosis.

Keywords: Anemia, Transfusion, Mechanical ventilation, Weaning, Mortality, Nosocomial infections

\footnotetext{
* Correspondence: alessandro.ghiani@klinik-schillerhoehe.de

This work was performed at the Schillerhoehe Lung Clinic, Gerlingen (Germany).

${ }^{1}$ Department of Pneumology and Respiratory Medicine, Schillerhoehe Lung

Clinic (Robert Bosch Hospital GmbH, Stuttgart) Solitudestr. 18, 70839

Gerlingen, Germany

Full list of author information is available at the end of the article
}

(c) The Author(s). 2019 Open Access This article is distributed under the terms of the Creative Commons Attribution 4.0 International License (http://creativecommons.org/licenses/by/4.0/), which permits unrestricted use, distribution, and reproduction in any medium, provided you give appropriate credit to the original author(s) and the source, provide a link to the Creative Commons license, and indicate if changes were made. The Creative Commons Public Domain Dedication waiver (http://creativecommons.org/publicdomain/zero/1.0/) applies to the data made available in this article, unless otherwise stated. 


\section{Background}

Intubation and mechanical ventilation is a life-saving procedure for patients presenting with severe acute respiratory failure. The majority of patients can be weaned promptly on recovery and resolution of the underlying condition. However, $7-14 \%$ of patients remain ventilated longer than 7 days $[1,2]$, which is frequently followed by tracheostomy and transferal to specialized weaning and rehabilitation centers, with variable outcomes reported $[3,4]$. In virtually all critically ill patients hemoglobin levels decline below normal limits during their stay in the intensive care unit (ICU). Therefore, anemia is a very common comorbid condition at the time of admission to the weaning center [5]. In patients receiving longterm mechanical ventilation, the presence of anemia may interfere with their ability to wean from ventilatory support [6]. Nevertheless, although it seems reasonable to speculate that improving oxygen delivery, to overcome the increased workload on respiratory muscles during spontaneous breathing trials (SBT), will consequently facilitate weaning from mechanical ventilation, the hemoglobin threshold for transfusion that can best help achieve this goal is still undetermined. Only a few small case studies have investigated this question $[7,8]$, with no clear recommendations made in the existing guidelines [1, 9]. In the 1980s and later, studies were published that were indicative of an immunomodulatory effect [10] of red blood cell (RBC) transfusions in critically ill patients, describing an association with nosocomial infections (NI) [11-16], which in turn could adversely affect patients' outcome.

The aim of the present study was to describe the incidence and severity of anemia and to investigate the impact of RBC transfusion on weaning outcome, hospital mortality, and nosocomial infection rates in prolonged mechanically ventilated, tracheotomized patients, admitted to a specialized weaning center.

\section{Methods}

This is a retrospective, single-center, observational cohort study at a national weaning center in Germany. The 12-bed ward was established in 2006 and is part of the specialized lung clinic at Schillerhoehe (Gerlingen). The weaning unit is equipped to provide invasive (by tracheostomy tube) and non-invasive ventilatory support. Since the establishment of the unit, it has taken referrals from intensive care units across Germany. Main preconditions for referral of a patient were hemodynamic stability without need for vasopressors or inotropic agents, wakefulness without need for continuous sedation, and invasive mechanical ventilation by tracheostomy tube with a positive end-expiratory pressure less than $10 \mathrm{cmH}_{2} \mathrm{O}$ and a fraction of inspired oxygen less than 0.6 .
The study was approved by the local ethics committee, the need for informed consent was waived (ethics committee of the State Chamber of Physicians of Baden-Wuerttemberg).

\section{Patient selection}

All consecutive patients transferred to the weaning center between December 2011 and December 2016 were identified. Patients were included if they were referred because of evident failure to wean from mechanical ventilation and met the criteria of prolonged weaning, classified as Category 3 as defined by Boles and colleagues, based on the overall duration of weaning as well as the number of spontaneous breathing trials required to liberate the patient from the ventilator [1]. Patients were excluded if a tracheostomy existed before the acute illness or if a transfer to another hospital had to take place in the course of weaning and weaning outcome thus remained uncertain.

\section{Ventilator weaning}

Weaning was systematically performed according to the recommendations from the statement by Boles and colleagues [1] as well as to the national guidelines on prolonged weaning [9]. The process included protocolbased increasing periods of unassisted breathing through a tracheostomy collar, usually starting with a $30 \mathrm{~min}$ SBT, and then advancing with at most $2 \mathrm{~h}$ per day. Between $\mathrm{T}$ piece ventilation, patients were mechanically ventilated in the assisted-controlled ventilator mode in order to recover from the imposed work of breathing during their SBT [17]. Extensive use of non-invasive ventilation (NIV), avoidance of sedatives, attention to nutrition, proactive physiotherapy, and optimal therapy of comorbidities constituted the approach to weaning. RBC transfusion in the course of weaning was regulated in an in-house protocol, based on national recommendations on the use of blood products [18]. In principle, a restrictive transfusion strategy was recommended with a transfusion trigger of hemoglobin less than $7.0 \mathrm{~g} / \mathrm{dl}$, whereas it was $8.0 \mathrm{~g} / \mathrm{dl}$ in patients with cardiac comorbidities (coronary artery disease, cardiac surgery patients).

At the end of the weaning process, patients were further subclassified into Categories 3a, 3b, or 3c, based on the German guideline on prolonged weaning [9]. Category 3 a describes persistent spontaneous breathing for more than $72 \mathrm{~h}$ without concomitant clinical and laboratory signs of chronic ventilatory insufficiency. Category $3 \mathrm{~b}$ represents the transition from invasive ventilation to non-invasive home ventilation. Category $3 c$ is defined as weaning failure, corresponding to transition to permanent home ventilation by tracheostomy tube or death on ventilation in the course of weaning. 


\section{Data collection}

Data were retrospectively collected from referral letters and hospitals' electronic medical record and chart system. Patients' baseline characteristics on admission, such as demographic data and comorbidities, all hemoglobin values of each patient in the course of weaning as well as the number of transfused RBCs and transfusion episodes with the corresponding pre-transfusion hemoglobin values were collected. Anemia was defined as hemoglobin concentration $<14.0 \mathrm{~g} / \mathrm{dl}$ in males and $<12.0 \mathrm{~g} / \mathrm{dl}$ in females, respectively [19]. Patients' records were reviewed for new nosocomial infections more than 2 days after admission to the weaning unit and up to $48 \mathrm{~h}$ after completion of weaning, defined according to the revised 2008 criteria of the U.S. Centers for Disease Control and Prevention (CDC) [20]. Further data included weaning duration, hospital length of stay, and hospital mortality rates.

Additional details on data collection can be found in the online supplement [see Additional file 1].

\section{Statistical analysis}

Descriptive and frequency statistics were used to summarize patients' demographics and baseline characteristics. Differences in categorical variables between groups were analyzed using the Chi-square test or Fisher's exact test, as appropriate. The Student's $t$-test was used to examine differences in continuous variables.

Pearson correlation coefficient was used to analyze a possible association between the number of RBC transfusions and the number of nosocomial infections.

Univariate and multivariate regression analyses were used to assess the impact of RBC transfusion, mean hemoglobin concentration in the course of weaning, hemoglobin concentration on the day of admission to the weaning center, and further clinical parameters describing disease severity (APACHE-II score, Charlson comorbidity index, weaning duration), on weaning outcome measures, hospital mortality, and infectious complications. Results were adjusted for patients' baseline clinical characteristics, transfusion of FFP/platelets, and bleeding complications in the course of weaning. The results for nosocomial infections were adjusted for weaning duration.

The predictive performance of the hemoglobin concentration on the day of admission regarding survival was assessed with the receiver operating characteristic (ROC) curve, and the area under the ROC curve (AUC), which summarizes the performance in predicting hospital mortality, was calculated.

We considered $p<0.05$ to be statistically significant for all tests performed.

\section{Results}

In the described period, 378 patients met the inclusion criteria; a further 14 patients were excluded. The total population was divided into transfused $(\mathrm{T})$ and non- transfused (NT) patients; there were 168 (44.4\%) patients in the $\mathrm{T}$ group and 210 (55.6\%) patients in the NT group. Table 1 shows the baseline clinical characteristics of all patients and between the two groups on admission to the weaning center.

They differed significantly, transfused patients showed higher disease severity with a higher mean APACHE-II score, higher mean Charlson comorbidity index (CCI), and more ventilator days on admission. In the total population, $100 \%$ of male patients showed anemia on admission to the weaning center, as did $96 \%$ of female patients. Significantly lower hemoglobin levels were found in the T group $(8.5 \pm$ $1.0 \mathrm{~g} / \mathrm{dl}$ and $9.4 \pm 1.3 \mathrm{~g} / \mathrm{dl}$, respectively; $p<0.001$ ).

\section{RBC transfusion and weaning outcome}

Table 2 compares the results between the two groups.

In total, 4807 hemoglobin values were recorded in the course of weaning, 3175 in the $\mathrm{T}$ group and 1632 in the NT group. The mean of all median hemoglobin values of each patient was significantly lower in the $\mathrm{T}$ group than in the NT group $(8.9 \pm 0.8 \mathrm{~g} / \mathrm{dl}$ and $9.7 \pm 1.1 \mathrm{~g} / \mathrm{dl}$, respectively; $p<0.001$ ).

In the course of weaning, a total of 361 transfusion episodes were recorded, corresponding to the same number of pre-transfusion hemoglobin values. A total of 580 units of RBCs were transfused, with no transfusion reaction detected in the $\mathrm{T}$ group. The mean pre-transfusion hemoglobin concentration was $7.5 \pm 0.5 \mathrm{~g} / \mathrm{dl} ; 18.8 \%$ of pre-transfusion values were lower than $7.0 \mathrm{~g} / \mathrm{dl}, 67.9 \%$ were between $7.0 \mathrm{~g} / \mathrm{dl}$ and $8.0 \mathrm{~g} / \mathrm{dl}$, and $11.9 \%$ were between $8.0 \mathrm{~g} / \mathrm{dl}$ and $9.0 \mathrm{~g} / \mathrm{dl}$. There was a significant difference in the number of platelets and fresh frozen plasma (FFP) units transfused between the groups, with more products administered in the $\mathrm{T}$ group (4.8 and $0.0 \%$, respectively; $p<0.001$ ), although the absolute difference was low. In total, 185 patients (48.9\%) were transfused during their stay in the ICU. Based on the available data, the number of transfused $\mathrm{RBC}$ units per patient before admission did not differ between the two groups $(1.27 \pm 0.6$ and $1.18 \pm 0.7$, respectively; $p=0.156)$. The same applies to the transfusion of FFP and platelets $(0.84 \pm 0.9$ versus $0.84 \pm 0.9 ; p=0.990)$.

Patients in the $\mathrm{T}$ group had a significant longer duration of weaning, longer hospital length of stay and increased crude hospital mortality. Weaning failure (Category 3c) occurred in a higher percentage of transfused patients, although there was no difference in the proportion of patients with long-term ventilator dependency (either by face mask or by tracheostomy tube).

\section{Nosocomial infections}

Table 3 compares the results between the two groups.

One hundred fifty-eight patients, with a total of 210 nosocomial infections, were recorded. There were significantly more nosocomial infections in transfused patients. In 
Table 1 Clinical characteristics on admission to the weaning center

\begin{tabular}{|c|c|c|c|c|}
\hline & All patients $(n=378)$ & Transfused $(n=168)$ & Non-transfused $(n=210)$ & $P$ value $^{d}$ \\
\hline \multicolumn{5}{|l|}{ Clinical characteristics } \\
\hline Age (years) & $69.3( \pm 12.0)$ & $70.6( \pm 10.2)$ & $68.3( \pm 13.2)$ & $0.058^{a}$ \\
\hline Gender (male) & $229(60.6)$ & $100(59.5)$ & $129(61.4)$ & n.s. ${ }^{b}$ \\
\hline Body mass index $\left(\mathrm{kg} / \mathrm{m}^{2}\right)$ & $27.1( \pm 7.7)$ & $25.7( \pm 6.7)$ & $28.2( \pm 8.3)$ & $0.001^{a}$ \\
\hline Smoking history & $165(43.7)$ & $68(40.5)$ & $97(46.2)$ & n.s..$^{b}$ \\
\hline APACHE-II & $16.2( \pm 5.0)$ & $17.1( \pm 5.0)$ & $15.5( \pm 5.0)$ & $0.002^{a}$ \\
\hline Albumin $(g / d l)$ & $2.0( \pm 0.5)$ & $1.9( \pm 0.5)$ & $2.1( \pm 0.5)$ & $0.002^{a}$ \\
\hline No. of patients with anemia & $372(98.4)$ & $167(99.4)$ & $205(97.6)$ & n.s. ${ }^{b}$ \\
\hline Hemoglobin on the day of admission $(\mathrm{g} / \mathrm{dl}$ ) & $9.0( \pm 1.3)$ & $8.5( \pm 1.0)$ & $9.4( \pm 1.3)$ & $<0.001^{a}$ \\
\hline Ventilator days on admission & $28.4( \pm 19.9)$ & $31.4( \pm 22.0)$ & $26.0( \pm 17.7)$ & $0.010^{a}$ \\
\hline Time from ETI to tracheostomy (days) & $10.2( \pm 7.0)$ & $11.0( \pm 7.7)$ & $9.5( \pm 6.4)$ & $0.035^{a}$ \\
\hline ECLA & $20(5.3)$ & $10(6.0)$ & $10(4.8)$ & n.s. ${ }^{b}$ \\
\hline \multicolumn{5}{|l|}{ Comorbidities } \\
\hline No. of comorbidities per patient & $2.1( \pm 1.6)$ & $2.1( \pm 1.5)$ & $2.0( \pm 1.6)$ & n.s. ${ }^{a}$ \\
\hline Charlson comorbidity index & $6.2( \pm 2.6)$ & $6.7( \pm 2.2)$ & $5.9( \pm 2.8)$ & $0.001^{a}$ \\
\hline COPD & $103(27.2)$ & $37(22.0)$ & $66(31.4)$ & $0.041^{b}$ \\
\hline Coronary artery disease & $113(29.9)$ & $59(35.1)$ & $54(25.7)$ & $0.047^{b}$ \\
\hline Left ventricular dysfunction (systolic) & $83(22.0)$ & $46(27.4)$ & $37(17.6)$ & $0.023^{b}$ \\
\hline Renal insufficiency (GFR < $60 \mathrm{ml} / \mathrm{min})$ & $88(23.3)$ & $52(31.0)$ & $36(17.1)$ & $0.001^{b}$ \\
\hline Hepatopathy & $22(5.8)$ & $12(7.1)$ & $10(4.8)$ & n.s. ${ }^{b}$ \\
\hline Diabetes mellitus & $114(30.2)$ & $45(26.8)$ & $69(32.9)$ & n.s. \\
\hline Neuromuscular disease & $21(5.6)$ & $6(3.6)$ & $15(7.1)$ & n.s..$^{b}$ \\
\hline Interstitial lung disease & $21(5.6)$ & $8(4.8)$ & $13(6.2)$ & n.s. ${ }^{b}$ \\
\hline Malignancy (active) & $39(10.3)$ & $20(11.9)$ & $19(9.1)$ & n.s. ${ }^{b}$ \\
\hline Immunosuppression & $49(13.0)$ & $20(11.9)$ & $29(13.8)$ & n.s. ${ }^{b}$ \\
\hline \multicolumn{5}{|l|}{ Cause of acute respiratory failure } \\
\hline Pneumonia & $124(32.8)$ & $49(29.2)$ & $75(35.7)$ & n.s. \\
\hline Sepsis (incl. Septic shock) & $33(8.7)$ & $16(9.5)$ & $17(8.1)$ & n.s. ${ }^{b}$ \\
\hline Acute exacerbation of COPD & $36(9.5)$ & $6(3.6)$ & $30(14.3)$ & $<0.001^{b}$ \\
\hline Cardiac failure & $12(3.2)$ & $2(1.2)$ & $10(4.8)$ & $0.049^{b}$ \\
\hline Cardiopulmonary resuscitation & $31(8.2)$ & $20(11.9)$ & $11(5.2)$ & $0.019^{b}$ \\
\hline Surgery & $94(24.9)$ & $57(33.9)$ & 37 (17.6) & $<0.001^{b}$ \\
\hline Cardiac surgery & $39(10.3)$ & $27(16.1)$ & $12(5.7)$ & $0.001^{b}$ \\
\hline Thoracic surgery & $32(8.5)$ & $19(11.3)$ & $13(6.2)$ & n.s. ${ }^{b}$ \\
\hline Abdominal surgery & $14(3.7)$ & $7(4.2)$ & $7(3.3)$ & n.s. ${ }^{b}$ \\
\hline Other & $9(2.4)$ & $4(2.4)$ & $5(2.4)$ & n.s. ${ }^{b}$ \\
\hline Trauma & $9(2.4)$ & $4(2.4)$ & $5(2.4)$ & n.s. ${ }^{b}$ \\
\hline Other & 39 (10.3) & $14(8.3)$ & 25 (11.9) & n.s. \\
\hline
\end{tabular}

Legend

Continuous variables are presented as mean values ( \pm standard deviation); categorical variables are presented as number (\%).

$a$ : Student's $t$-test

: : Chi square test

c: Fisher's exact test

${ }^{d} \mathrm{P}$ value for differences between transfused and non-transfused patients

Abbreviations: n.s. not significant ( $p>0.05)$, APACHE-II Acute physiology and chronic health evaluation II score, ETI Endotracheal intubation, ECLA Extracorporeal

lung assistance (in acute respiratory failure), no. number, COPD Chronic obstructive pulmonary disease, GFR Glomerular filtration rate 
Table 2 Red blood cell transfusion and weaning outcome

\begin{tabular}{|c|c|c|c|c|}
\hline Result & All patients $(n=378)$ & Transfused $(n=168)$ & Non-transfused $(n=210)$ & $P$ value $^{e}$ \\
\hline \multicolumn{5}{|l|}{ RBC transfusion } \\
\hline Mean hemoglobin in the course of weaning $(\mathrm{g} / \mathrm{dl})^{a}$ & $9.3( \pm 1.0)$ & $8.9( \pm 0.8)$ & $9.7( \pm 1.1)$ & $<0.001^{\mathrm{b}}$ \\
\hline Pre-transfusion hemoglobin value (g/dl) & $7.5( \pm 0.5)$ & $7.5( \pm 0.5)$ & & - \\
\hline No. of transfusion episodes & 361 & 361 & & - \\
\hline Transfusion episodes per patient & $1.0( \pm 1.6)$ & $2.2( \pm 1.9)$ & & - \\
\hline No. of transfused RBC units & 580 & 580 & & - \\
\hline RBC units per patient & $1.5( \pm 2.9)$ & $3.5( \pm 3.6)$ & & - \\
\hline Transfusion reactions & $0(0.0)$ & $0(0.0)$ & & \\
\hline Transfusion of FFP and/or platelets & $8(2.1)$ & $8(4.8)$ & $0(0.0)$ & $<0.001^{\mathrm{c}}$ \\
\hline Bleeding complications & $21(5.6)$ & $17(10.1)$ & $4(1.9)$ & $<0.001^{\mathrm{d}}$ \\
\hline Gastrointestinal bleeding & $12(3.2)$ & $10(5.6)$ & $2(1.0)$ & n.s. ${ }^{d}$ \\
\hline Other bleeding events & $9(2.4)$ & $7(4.2)$ & $2(1.0)$ & n.s. ${ }^{d}$ \\
\hline \multicolumn{5}{|l|}{ Weaning outcome } \\
\hline Weaning success (Category 3a/3b) & $264(69.8)$ & $107(63.7)$ & $157(74.8)$ & $0.020^{d}$ \\
\hline Category 3a & $191(50.5)$ & $84(78.5)$ & $107(68.2)$ & n.s. ${ }^{d}$ \\
\hline Category $3 b$ & $73(19.3)$ & $23(21.5)$ & $50(31.8)$ & $0.013^{d}$ \\
\hline Weaning failure (Category 3c) & $114(30.2)$ & $61(36.3)$ & $53(25.2)$ & $0.022^{d}$ \\
\hline Invasive HMV & $101(26.7)$ & $51(30.4)$ & $50(23.8)$ & n.s. ${ }^{d}$ \\
\hline Death on ventilation & $13(3.4)$ & $10(5.6)$ & $3(1.4)$ & $0.016^{d}$ \\
\hline Long-term ventilator dependency ${ }^{f}$ & $174(46.0)$ & $74(44.0)$ & $100(47.6)$ & n.s. ${ }^{d}$ \\
\hline Weaning duration (days) & $23.0( \pm 16.2)$ & $29.9( \pm 20.0)$ & $17.5( \pm 9.1)$ & $<0.001^{b}$ \\
\hline Hospital length of stay (days) & $48.0( \pm 33.9)$ & $57.7( \pm 44.1)$ & $39.0( \pm 26.4)$ & $<0.001^{b}$ \\
\hline Hospital mortality & 45 (11.9) & $31(18.5)$ & $14(6.7)$ & $<0.001^{d}$ \\
\hline $\begin{array}{l}\text { Legend } \\
\text { Results are presented as mean values ( } \pm \text { standard deviation } \\
a_{:}: \text {Mean of all median hemoglobin values of each patient in } \\
b: \text { Student's } t \text {-test } \\
c_{\text {: }} \text { Fisher's exact test } \\
d_{\text {: }} \text { :hi square test } \\
e^{P} P \text { value for differences between transfused and non-transf } \\
{ }^{f} \text { Summary of patients categorized as } 3 \mathrm{~b} \text { or } 3 \mathrm{c} \text {-Invasive HM }\end{array}$ & $\begin{array}{l}\text { umber or number }(\%) \text {. } \\
\text { course of weaning } \\
\text { d patients }\end{array}$ & & & \\
\hline
\end{tabular}

particular, ventilator-associated pneumonia (VAP) was more common in the $\mathrm{T}$ group than in the NT group (13.1 and $1.0 \%$, respectively; $p<0.001$ ), with no significant differences detected in the other specific types of infections. There was only one patient with multiple occurrence of the same type of infection (two gastroenteritis infections).

Additional file 2: Tables S1 and S2 compare the number and percentage of different isolated pathogens between the two groups according to the type of nosocomial infection; Additional file 2: Figure S1 shows the percentage of different pathogens in patients with nosocomial infections [see Additional file 2].

\section{Results of multivariate analyses}

Table 4 shows the results of the univariate and multivariate analyses of the impact of $\mathrm{RBC}$ transfusion on the selected endpoints.
RBC administration was independently correlated with the duration of weaning and hospital length of stay, but not with weaning failure (Category 3c); there was also a trend toward increased hospital mortality. Pearson correlation revealed a significant association of the number of transfused RBCs with the number of nosocomial infections (Pearson correlation coefficient $0.352 ; p<0.001$ ), but there was no independent correlation of RBCs with nosocomial infections in multivariate analysis.

Mean hemoglobin concentration in the course of weaning was correlated with weaning failure (Category 3c) in univariate, but not in multivariate analysis. There was also no independent correlation with the duration of weaning (adjusted $\beta-0.100,95 \%$ CI $-0.163-0.166$; $p=0.683$ ) or with hospital mortality (adjusted $\beta 0.975$, 95\% CI 0.936-1.015; $p=0.420$ ). 
Table 3 Nosocomial infections according to CDC criteria

\begin{tabular}{|c|c|c|c|c|}
\hline & All patients $(n=378)$ & Transfused $(n=168)$ & Non-transfused $(n=210)$ & $P$ value $^{d}$ \\
\hline No. of patients with nosocomial infections & $158(41.8)$ & $91(54.2)$ & $67(31.9)$ & $\overline{<0.001^{a}}$ \\
\hline No. of patients with MDR-NI & $24(15.2)$ & $16(17.6)$ & $8(11.9)$ & n.s. ${ }^{a}$ \\
\hline No. of nosocomial infections & 210 & 133 & 77 & - \\
\hline No. of MDR-NI & $28(13.3)$ & $20(15.0)$ & $8(10.4)$ & n.s. ${ }^{a}$ \\
\hline No. of NI per patient & $0.56( \pm 0.78)$ & $0.79( \pm 0.92)$ & $0.37( \pm 0.57)$ & $<0.001^{c}$ \\
\hline \multicolumn{5}{|l|}{ No. of nosocomial infections by site/type } \\
\hline Lower respiratory tract infection & $72(19.0)$ & $48(28.7)$ & $24(11.4)$ & $<0.001^{a}$ \\
\hline Ventilator-associated pneumonia & $24(6.4)$ & $22(13.1)$ & $2(1.0)$ & $<0.001^{a}$ \\
\hline Tracheobronchitis & $48(12.7)$ & $26(15.5)$ & $22(10.5)$ & n.s. ${ }^{a}$ \\
\hline Urinary tract infection & $61(16.1)$ & $32(19.0)$ & $29(13.8)$ & n.s. ${ }^{a}$ \\
\hline Gastroenteritis & $32(8.5)$ & $20(11.9)$ & $12(5.7)$ & n.s. ${ }^{a}$ \\
\hline Clostridium-associated infection & $29(7.7)$ & $17(10.1)$ & $12(5.7)$ & \\
\hline Norovirus infection & $3(0.8)$ & $3(1.8)$ & $0(0.0)$ & \\
\hline Decubitus infection & $7(1.9)$ & $5(3.0)$ & $2(1.0)$ & n.s. ${ }^{b}$ \\
\hline Catheter-related BSI & $22(5.8)$ & $13(7.7)$ & $9(4.3)$ & n.s. ${ }^{a}$ \\
\hline Other & $16(4.2)$ & $15(8.9)$ & $1(0.5)$ & $<0.001^{b}$ \\
\hline Biliary tract infection & 1 & 1 & 0 & \\
\hline Lung abscess and empyema & 1 & 1 & 0 & \\
\hline Endocarditis & 1 & 1 & 0 & \\
\hline Laboratory-confirmed BSI & 3 & 3 & 0 & \\
\hline Mediastinitis & 1 & 1 & 0 & \\
\hline Peritonitis (primary/secondary) & 3 & 3 & 0 & \\
\hline Skin and soft tissue infection & 1 & 1 & 0 & \\
\hline Surgical site infection & 5 & 4 & 1 & \\
\hline No. of isolated pathogens & 241 & 153 & 88 & - \\
\hline No. of isolated MDR pathogens & $30(12.4)$ & $21(13.7)$ & $9(10.2)$ & n.s. ${ }^{a}$ \\
\hline Time to $1_{\text {st }}$ nosocomial infection (days) & $14.7( \pm 11.4)$ & $16.4( \pm 12.3)$ & $12.5( \pm 9.7)$ & $0.030^{c}$ \\
\hline
\end{tabular}

Legend

Results are presented as mean values ( \pm standard deviation), number, or number (\%)

a: Chi square test

$b$ : Fisher's exact test

$c$ : Student's $t$-test

$d: P$ value for differences between transfused and non-transfused patients

Abbreviations: No. Number, n.s. not significant $(p>0.05), B S I$ Bloodstream infection, MDR Multidrug resistant, NI Nosocomial infection

Table 4 Impact of red blood cell transfusion on outcome parameters: Results of univariate and multivariate analyses

\begin{tabular}{|c|c|c|c|c|}
\hline Outcome & Unadjusted OR (95\% Cl) & $P$ value & Adjusted OR (95\% Cl) & $P$ value \\
\hline Weaning failure (Category 3c) & $1.689(1.085-2.629)$ & 0.020 & - & n.s. ${ }^{a}$ \\
\hline Hospital mortality & $3.168(1.625-6.177)$ & 0.001 & $2.050(0.995-4.224)$ & $0.052^{a}$ \\
\hline Nosocomial infections & $2.522(1.625-6.177)$ & $<0.001$ & - & n.s. ${ }^{a}$ \\
\hline Outcome & Unadjusted $\beta(95 \% \mathrm{Cl})$ & $P$ value & Adjusted $\beta(95 \% \mathrm{Cl})$ & $P$ value \\
\hline Weaning duration & $12.386(9.335-15.436)$ & $<0.001$ & $12.386(9.335-15.436)$ & $<0.001^{b}$ \\
\hline Hospital length of stay & $18.664(11.464-25.864)$ & $<0.001$ & $16.116(8.925-23.306)$ & $<0.001^{b}$ \\
\hline
\end{tabular}

\section{Legend}

a: Logistic regression analysis

$b$ : Linear regression analysis

Results were adjusted for baseline demographics and clinical characteristics (age, gender, body mass index, APACHE-II, Albumin, hemoglobin on admission, smoking history), comorbidities (Charlson comorbidity index, COPD, renal insufficiency), causes of acute respiratory failure (acute exacerbation of COPD, cardiopulmonary resuscitation, cardiac failure, surgery) as well as for mean hemoglobin, FFP/platelets, gastrointestinal bleeding, and other bleeding events in the course of weaning. The results for nosocomial infections were adjusted for weaning duration.

Abbreviations: OR Odds ratio, 95\% Cl 95\% confidence interval, n.s. not significant $(p>0.05)$ 
Hemoglobin concentration on the day of admission was an independent risk factor for hospital mortality (adjusted OR $0.956,95 \%$ CI $0.924-0.989 ; p=0.010$ ). Analysis of the associated ROC shows a statistically significant result $(\mathrm{AUC}=0.670,95 \%$ CI 0.593-0.747; $p<0.001)$. Hemoglobin on admission of less than $8.5 \mathrm{~g} / \mathrm{dl}$ was associated with increased mortality, but with low sensitivity of $67 \%$ and specificity of $63 \%$. Based on the descriptive statistics, hospital mortality for hemoglobin on admission below $8.5 \mathrm{~g} / \mathrm{dl}$ was $17.7 \%$, whereas it was $8.5 \%$ for values above $8.5 \mathrm{~g} / \mathrm{dl}$.

APACHE-II score on admission was independently correlated with hospital length of stay (adjusted $\beta$ 0.582, 95\% CI 0.042-1.122; $p=0.035$ ), and the CCI was an independent risk factor for hospital mortality (adjusted OR $1.249,95 \%$ CI $1.094-1.425 ; p=0.001$ ).

Finally, the duration of weaning could be identified as the only independent risk factor for nosocomial infections (adjusted OR 1.065, 95\% CI 1.045-1.076; $p<0.001$ ).

\section{Discussion}

The present study describes for the first time transfusion practice in prolonged mechanically ventilated, tracheotomized patients, treated at a specialized weaning center after surviving acute respiratory insufficiency. So far, there are only a few studies [3, 4] on this group of patients and the impact of $\mathrm{RBC}$ transfusion on weaning outcome, occurrence of nosocomial infections and survival has not yet been investigated.

An essential finding of the present study is that transfused patients differed significantly from those who were not transfused in the course of weaning regarding their clinical characteristics on admission. Patients in the $\mathrm{T}$ group appeared to be more diseased, recognizable by higher APACHE-II scores, lower levels of albumin and hemoglobin, and a larger proportion of cardiac comorbidities and renal insufficiency. The proportion of postoperative and in particular cardiac surgery patients was increased, in which postoperative blood loss may have led to lower hemoglobin levels on admission and more $\mathrm{RBC}$ transfusions in the course of weaning. These points may help explain the lower hemoglobin level on admission to the weaning center and the lower average hemoglobin concentration in transfused patients.

Anemia is common in the ICU [5], so the observed high prevalence on admission to the weaning center is not surprising. Only $18.8 \%$ of transfused patients showed hemoglobin concentrations below $7.0 \mathrm{~g} / \mathrm{dl}$ prior to RBC administration and the mean pre-transfusion hemoglobin value was $7.5 \mathrm{~g} / \mathrm{dl}( \pm 0.5 \mathrm{~g} / \mathrm{dl})$ which is, at first sight, higher then would be expected from recommendations of current guidelines $[18,21,22]$. This could be due to several reasons. First, the proportion of patients with concomitant coronary artery disease was $35.1 \%$, and a total of $16.1 \%$ of patients in the $\mathrm{T}$ group had undergone cardiac surgery immediately prior to admission to the weaning center. In fact, current guidelines recommend a transfusion trigger of $8.0 \mathrm{~g} / \mathrm{dl}$ in this subgroup of patients $[18,22]$. Second, the lack of clinical studies regarding $\mathrm{RBC}$ administration in prolonged mechanically ventilated patients may have led to transfusions outside of evidence based guidelines. Current guidelines recommend a restrictive transfusion strategy in critically ill patients without concomitant cardiovascular diseases [21, 22], but it is still uncertain whether this can be applied simply to prolonged mechanically ventilated patients. Third, there were 17 patients in the $\mathrm{T}$ group with acute bleeding complications. In such patients, decreased hemoglobin values are not always evident and clinical parameters other than hemoglobin level, such as hemodynamic instability or shock, may have led to RBC transfusion [23]. Fourth, there has been a protocolized approach to RBC transfusion in all patients, but since this was a retrospective study, we cannot completely rule out deviations from the protocol [24]. Overall, this may explain the proportion of approximately $68 \%$ of patients transfused with a pre-transfusion hemoglobin level of $7-8 \mathrm{~g} / \mathrm{dl}$ in the present study.

Transfused patients showed worse outcomes compared to non-transfused patients. Again, differences in clinical characteristics may have played a crucial role. Previous work has shown that a higher APACHE-II score in critically ill patients is associated with a longer ICU stay, prolonged mechanical ventilation, and increased mortality [25]. The significantly increased number of ventilator days on admission in the $\mathrm{T}$ group may be indicative of a more complicated course in the ICU. The fact that CCI was independently correlated with hospital mortality may indicate the importance of concomitant diseases in terms of survival. However, our results are in line with previous observational studies [12-15, 26, 27], where RBC administration after adjustment for differences in clinical characteristics between transfused and non-transfused patients, remained independently correlated with worse outcomes. In controlled trials with a well-balanced distribution of patient characteristics in the intervention and control group, comparing a restrictive and a liberal transfusion strategy in different ICU patients, contradictory results were found, which at present do not allow a definitive statement on the impact of RBC transfusion on the above mentioned outcomes [28-35].

Our results are not indicative of an independent association of RBC transfusion and weaning outcome. Although from a pathophysiological point of view improvement in oxygen transport capacity could facilitate sustained spontaneous breathing, there is currently no evidence, except for a small case series [7], to support the assumption that transfusions in anemic patients may reduce the duration of mechanical ventilation or affect weaning outcome [6]. 
Patients in the $\mathrm{T}$ group showed significantly more nosocomial infections; in particular VAP was more frequent. Previous studies that compared transfused with non-transfused patients in the ICU came to similar conclusions, identifying transfusions as an independent risk factor for nosocomial infections [12-14, 16, 26, 36, 37]. In the present study, there was no independent correlation of RBC transfusion and the occurrence of infectious complications. This may have different reasons. First, patients in both groups were transfused in the ICU so that a sustained immunomodulatory effect in the course of weaning cannot be ruled out. Second, all RBC transfusions were recorded during the weaning period regardless of the time of onset of nosocomial infection. Thus, some RBC units could have been administered after the occurrence of a nosocomial infection. Third, the only independent risk factor for nosocomial infections was the duration of weaning. A patient with a longer hospital stay is more likely to have a NI than a patient with a short stay, in particular the risk of VAP increases with prolonged ventilation [36]. Since the duration of weaning was significantly longer in the $\mathrm{T}$ group, this may help explain the higher percentage of NI and especially of VAP. In keeping with this hypothesis, there was no independent correlation of RBC transfusion with nosocomial infection after adjustment for weaning duration. Fourth, the way in which nosocomial infections were detected may have played a role. Previous work has used different definitions of nosocomial infections [1214, 38], a significant proportion has been detected on the basis of clinical criteria, but without isolation of a pathogen. This increases the number of clinical events falsely detected as infection. In the present study, nosocomial infections were recorded based on the revised 2008 CDC criteria [20], validated for surveillance purposes $[15,39]$. Based on these criteria, a proof of a pathogen is mandatory for the majority of the diagnoses. Again, this is more likely to underestimate the incidence of NI, because in the ICU in approximately $30 \%$ no pathogen detection succeeds [40]. Consequently, the frequencies of nosocomial infections vary between studies $[13,14,39]$ and this may well have led to confounding of results within the studies. Looking at the randomized controlled trials that examined the impact of RBC transfusion on nosocomial infection rates, the picture is relatively consistent [30, 33, 41]. So far, no controlled study has proven a strong causal link between transfusions and nosocomial infections. Thus, all these trials probably indicate that surveillance studies may overestimate the risk of RBC administration for nosocomial infections.

Our study has several limitations. Due to the singlecenter design, the results are probably not transferable to other centers. Our results do not support a causal relationship between $\mathrm{RBC}$ administration and the significantly correlated endpoints; this requires a controlled trial. No information was provided on storage time, although all transfused RBCs were stored with saline-adenine-glucosemannitol (SAG-M) and were leucocyte-depleted. We didn't check medical records for anticoagulant/ antiplatelet therapy and apart from bleeding complications, other non-infectious complications in the course of weaning, which also could have had an impact on the endpoints we considered, were not recorded.

\section{Conclusions}

Ninety-eight percent of prolonged mechanically ventilated patients showed anemia on admission to the weaning center. In multivariate analyses, RBC transfusion was independently correlated with weaning duration and hospital length of stay. There was also a trend toward increased hospital mortality, but there was no independent correlation with weaning outcome or nosocomial infections. Since transfused and non-transfused patients differed significantly regarding their clinical characteristics, RBC transfusion might be an indicator of disease severity rather than directly impacting patient prognosis.

\section{Supplementary information}

Supplementary information accompanies this paper at https://doi.org/10. 1186/s12890-019-1009-1.

Additional file 1. Supplemental methods; details on data collection and criteria for nosocomial infections.

Additional file 2: Table S1, Comparison of number and percentage of different isolated pathogens according to the type of nosocomial infection; Table S2. Comparison of number of different isolated MDR pathogens according to the type of nosocomial infection; Figure S1. Percentage of different pathogens in patients with nosocomial infections.

\section{Abbreviations}

95\% Cl: 95\% confidence interval; APACHE-II: Acute Physiology and Chronic Health Evaluation (score) 2; ARDS: Acute respiratory distress syndrome; AUC: Area under the curve; BSI: Bloodstream infection; CCl: Charlson comorbidity index; CDC: Centers for disease control and prevention; COPD: Chronic obstructive pulmonary disease; FFP: Fresh frozen plasma; ICU: Intensive care unit; I-HMV: Invasive home (mechanical) ventilation; MDR: Multidrug resistant; NI: Nosocomial infection; NIV: Non-invasive ventilation; NT group: Non-transfused group; OR: Odds ratio; RBC: Packed red blood cells; ROC: Receiver operating characteristic curve; SBT: Spontaneous breathing trial; SD: Standard deviation; T group: Transfused group; VAP: Ventilator-associated pneumonia

\section{Acknowledgements}

Not applicable.

\section{Authors' contributions}

All authors had full access to all of the data in the study. AG serves as guarantor of the paper, contributed to data acquisition, and takes responsibility for the integrity of the data and the accuracy of the data analysis. AS contributed to data acquisition, data analysis, data interpretation and revision of the manuscript. GS planned and performed the statistical analysis. CN contributed to data analysis, data interpretation, and revision of the manuscript. All authors have read and approved the final version of the manuscript. 
Funding

None.

\section{Availability of data and materials}

The datasets used and/or analyzed during the current study are available from the corresponding author on reasonable request.

\section{Ethics approval and consent to participate}

The study was approved by the local ethics committee, the need for informed consent was waived (ethics committee of the State Chamber of Physicians of Baden-Wuerttemberg, Germany, file number F-2016-122).

\section{Consent for publication}

Not applicable.

\section{Competing interests}

A. G. has received travel grants from Bayer AG and Teva GmbH. C. N. has received honoraria for lectures and served on advisory boards for Boehringer Ingelheim and Roche. The remaining authors have disclosed that they do not have any conflicts of interest.

\section{Author details}

${ }^{1}$ Department of Pneumology and Respiratory Medicine, Schillerhoehe Lung Clinic (Robert Bosch Hospital GmbH, Stuttgart) Solitudestr. 18, 70839 Gerlingen, Germany. ${ }^{2}$ Athens, Greece. ${ }^{3}$ Cologne, Germany. ${ }^{4}$ Munich, Germany.

Received: 25 February 2019 Accepted: 25 November 2019

Published online: 18 December 2019

\section{References}

1. Boles JM, Bion J, Connors A, et al. Weaning from mechanical ventilation. Eur Respir J. 2007:29:1033-56.

2. Funk GC, Anders S, Breyer MK, et al. Incidence and outcome of weaning from mechanical ventilation according to new categories. Eur Respir J. 2010; 35:88-94.

3. Pilcher DV, Bailey MJ, Treacher DF, et al. Outcomes, cost and long term survival of patients referred to a regional weaning Centre. Thorax. 2005;60: 187-92.

4. Bonnici DM, Sanctuary T, Warren A, et al. Prospective observational cohort study of patients with weaning failure admitted to a specialist weaning, rehabilitation and home mechanical ventilation Centre. BMJ Open. 2016;6:e10025.

5. Hayden SJ, Albert TJ, Watkins TR, et al. Anemia in critical illness: insights into etiology, consequences, and management. Am J Respir Crit Care Med. 2012; 185:1049-57.

6. Silver MR. Anemia in the long-term ventilator-dependent patient with respiratory failure. Chest. 2005;128:568-75.

7. Schönhofer B, Böhrer $H$, Köhler D. Blood transfusion facilitating difficult weaning from the ventilator. Anaesthesia. 1998;53:181-4.

8. Schönhofer B, Wenzel M, Geibel M, et al. Blood transfusion and lung function in chronically anemic patients with severe chronic obstructive pulmonary disease. Crit Care Med. 1998;26:1824-8.

9. Schönhofer B, Geiseler J, Dellweg D, et al. Prolonged weaning: S2k-guideline published by the German respiratory society. Pneumologie. 2014;68:19-75.

10. Vamvakas EC. Possible mechanisms of allogeneic blood transfusionassociated postoperative infection. Transfus Med Rev. 2002;16:144-60.

11. Edna TH, Bjerkeset T. Association between blood transfusion and infection in injured patients. J Trauma. 1992;33:659-61.

12. Taylor RW, Manganaro L, O'Brien J, et al. Impact of allogenic packed red blood cell transfusion on nosocomial infection rates in the critically ill patient. Crit Care Med. 2002;30:2249-54.

13. Taylor RW, O'Brien J, Trottier SJ, et al. Red blood cell transfusions and nosocomial infections in critically ill patients. Crit Care Med. 2006:34:2302-8.

14. Rachoin JS, Daher R, Schorr C, et al. Microbiology, time course and clinical characteristics of infection in critically ill patients receiving packed red blood cell transfusion. Vox Sang. 2009:97:294-302

15. Park DW, Chun BC, Kwon SS, et al. Red blood cell transfusions are associated with lower mortality in patients with severe sepsis and septic shock: a propensity-matched analysis. Crit Care Med. 2012;40:3140-5.

16. Dupuis C, Garrouste-Orgeas M, Bailly S, et al. Effect of transfusion on mortality and other adverse events among critically ill septic patients: an observational study using a marginal structural cox model group. Crit Care Med. 2017:45:1972-80

17. Jubran A, Grant BJ, Duffner LA, et al. Effect of pressure support vs unassisted breathing through a tracheostomy collar on weaning duration in patients requiring prolonged mechanical ventilation: a randomized trial. JAMA. 2013; 309:671-7.

18. Müller M, Geisen C, Zacharowski K, et al. Transfusion of packed red cellsindications, triggers and adverse events. Dtsch Arztebl Int. 2015;112:507-18.

19. Beutler $E$, Waalen J. The definition of anemia: what is the lower limit of normal of the blood hemoglobin concentration. Blood. 2006;107:1747-50.

20. Horan TC, Andrus M, Dudeck MA. CDC/NHSN surveillance definition of health care-associated infection and criteria for specific types of infections in the acute care setting. Am J Infect Control. 2008;36:309-32.

21. Retter $A$, Wyncoll $D$, Pearse $R$, et al. Guidelines on the management of anaemia and red cell transfusion in adult critically ill patients. Br J Haematol. 2013;160:445-64.

22. Carson JL, Guyatt G, Heddle NM, et al. Clinical practice guidelines from the AABB: red blood cell transfusion thresholds and storage. JAMA. 2016;316:2025-35.

23. Corwin HL, Gettinger A, Pearl RG, et al. The CRIT study: Anemia and blood transfusion in the critically ill_-current clinical practice in the United States. Crit Care Med. 2004;32:39-52.

24. Seitz KP, Sevransky JE, Martin GS, et al. Evaluation of RBC transfusion practice in adult ICUs and the effect of restrictive transfusion protocols on routine care. Crit Care Med. 2017:45:271-81.

25. Sudarsanam TD, Jeyaseelan $L$, Thomas K, et al. Predictors of mortality in mechanically ventilated patients. Postgrad Med J. 2005:81:780-3.

26. Zilberberg MD, Stern LS, Wiederkehr DP, et al. Anemia, transfusions and hospital outcomes among critically ill patients on prolonged acute mechanical ventilation: a retrospective cohort study. Crit Care. 2008;12:R60.

27. Lai YC, Ruan SY, Huang CT, et al. Hemoglobin levels and weaning outcome of mechanical ventilation in difficult-to-wean patients: a retrospective cohort study. PLoS One. 2013;8:e73743.

28. Hebert PC, Wells G, Blajchman MA, et al. A multicenter, randomized, controlled clinical trial of transfusion requirements in critical care. N Engl J Med. 1999:340:409-17.

29. Hebert PC, Blajchman MA, Cook DJ, et al. Do blood transfusions improve outcomes related to mechanical ventilation? Chest. 2001:119:1850-7.

30. Villanueva C, Colomo A, Bosch A, et al. Transfusion strategies for acute upper gastrointestinal bleeding. N Engl J Med. 2013;368:11-21.

31. Walsh TS, Boyd JA, Watson D, et al. Restrictive versus Liberal transfusion strategies for older mechanically ventilated critically ill patients: a randomized pilot trial. Crit Care Med. 2013:41:2354-63.

32. Holst LB, Haase N, Wetterslev J, et al. Lower versus higher hemoglobin threshold for transfusion in septic shock. N Engl J Med. 2014;371:1381-91.

33. Murphy GJ, Pike K, Rogers CA, et al. Liberal or restrictive transfusion after cardiac surgery. N Engl J Med. 2015;372:997-1008.

34. Mazer CD, Whitlock RP, Fergusson DA, et al. Restrictive or liberal red-cel transfusions for cardiac surgery. N Engl J Med. 2017:377:2133-44.

35. Bergamin FS, Almeida JP, Landoni G, et al. Liberal versus restrictive transfusion strategy in critically ill oncologic patients: the transfusion requirements in critically ill oncologic patients randomized controlled trial. Crit Care Med. 2017;45:766-73.

36. Shorr AF, Duh MS, Kelly KM, et al. Red blood cell transfusion and ventilatorassociated pneumonia: a potential link? Crit Care Med. 2004;32:666-74.

37. Shorr AF, Jackson WL, Kelly KM, et al. Transfusion practice and blood stream infections in critically ill patients. Chest. 2005;127:1722-8.

38. Pingleton SK, Fagon JY, Leeper KV Jr, et al. Patient selection for clinical investigation of ventilator-associated pneumonia: criteria for evaluating diagnostic techniques. Chest. 1992:102:553-6.

39. Engele LJ, Straat M, van Rooijen IHM, et al. Transfusion of platelets, but not of red blood cells, is independently associated with nosocomial infections in the critically ill. Ann Intensive Care. 2016;6:67.

40. Phua J, Ngerng W, See K, et al. Characteristics and outcomes of culturenegative versus culture-positive severe sepsis. Crit Care. 2013;17:R202.

41. Rohde JM, Dimcheff DE, Blumberg N, et al. Health care-associated infection after red blood cell transfusion: a systematic review and meta-analysis. JAMA. 2014;311:1317-26.

\section{Publisher's Note}

Springer Nature remains neutral with regard to jurisdictional claims in published maps and institutional affiliations. 